\title{
0 crescente impacto das publicações em espiritualidade e saúde e o papel da Revista de Psiquiatria Clínica
}

\author{
The growing impact of publications in spirituality and health and the role of Revista de Psiquiatria Clínica
}

\author{
AleXander Moreira-AlmeIDA ${ }^{1}$ \\ - Professor adjunto de Psiquiatria e Semiologia da Faculdade de Medicina da Universidade Federal de Juiz de Fora (UFJF). Diretor do Núcleo de Pesquisas em Espiritualidade e Saúde (Nupes) da \\ UFJF, Juiz de Fora, MG.
}

Recebido: 10/2/2010 - Aceito: 10/2/2010

Moreira-Almeida A / Rev Psiq Clín. 2010;37(2):41-2

As relações entre espiritualidade e saúde têm despertado um crescente interesse na comunidade acadêmica e na população em geral. Uma medida objetiva que reflete essa importância está no número de artigos indexados nas principais bases de dados internacionais na área de saúde. Em uma pesquisa realizada em 21/12/2009 com os termos de busca "religio *" e "spiritu*", identificamos 42.734 artigos no PubMed e 63.116 no PsycINFO. Deste total, quase metade foi publicada nesta última década, respectivamente, 18.478 e 27.100 artigos.

No Brasil, a Revista de Psiquiatria Clínica tem sido uma publicação atuando de modo pioneiro e relevante na expansão do conhecimento em espiritualidade e saúde. No fim de 2007, publicou um suplemento bilíngue (português e inglês) inteiramente dedicado à Espiritualidade e Saúde (vol. 34, supl. 1). Que temos notícia, no contexto mundial, foi a primeira vez em que uma revista de psiquiatria dedicou um fascículo inteiro ao tema. Também foi a primeira revista médica em língua portuguesa a fazer o mesmo. Esse suplemento, composto por artigos escritos por um total de 35 pesquisadores do Brasil e do exterior, tem alcançado uma excelente repercussão, evidenciando o interesse pelo tema. Desde sua publicação em outubro de 2007, o fascículo foi acessado 100.216 vezes na base de dados SciELO. Esses números colocam o suplemento como o segundo fascículo da Revista de Psiquiatria Clínica mais acessado nos últimos dois anos, sendo o primeiro um fascículo sobre transtornos alimentares publicado em 2004 (vol. 31, n. 4). Tem havido uma sensível repercussão internacional, já que o suplemento sobre espiritualidade já obteve 6.112 acessos de países como Portugal, Estados Unidos, Austrália e Irlanda. Importante destacar que esses dados subestimam o real acesso ao suplemento, posto que computam apenas os acessos via SciELO e não incluem os realizados diretamente pela página da Revista de Psiquiatria Clínica.

Faremos um breve comentário sobre os cinco artigos mais acessados desse suplemento em Espiritualidade e Saúde, que estão listados nas referências por ordem decrescente de acessos ${ }^{1-5}$. Eles nos proporcionam uma perspectiva da diversidade de tópicos abordados e que geram grande interesse no público acadêmico e clínico. $\mathrm{O}$ artigo mais acessado foi escrito pela psicóloga Raquel Panzini ${ }^{1}$ com um grupo de pesquisadores da Universidade Federal do Rio Grande do Sul (UFRGS), que revisaram as evidências sobre a relação entre espiritualidade e um desfecho positivo, dentro de uma visão mais ampliada de saúde, a qualidade de vida. Concluíram haver "indícios consistentes de associação entre qualidade de vida e espiritualidade/ religiosidade" 1 . Três outros artigos enfocaram aplicações de aspectos da espiritualidade na prática clínica. O neurologista Mario Peres et al. ${ }^{2}$ revisaram a literatura a respeito da importância da integração da espiritualidade na abordagem de pacientes que têm representado um crescente desafio no proporcionamento de cuidados adequados, aque- les portadores de dor crônica e os pacientes terminais². O psicólogo Júlio Peres et al. ${ }^{5}$ discutiram aspectos teóricos e ensaios clínicos sobre o necessário mas muitas vezes negligenciado aspecto da integração das dimensões espirituais/religiosas na psicoterapia, tendo em vista torná-las mais eficazes e aceitáveis por levarem em consideração o universo cultural de nossos pacientes ${ }^{5}$. A psicóloga Ana Catarina Elias ${ }^{4}$ forneceu um exemplo promissor do processo de desenvolvimento e avaliação de uma intervenção para pacientes terminais por ela desenvolvida com base nos relatos de pacientes que passaram por experiências de quase morte, que também foi tema de outro artigo no suplemento, escrito por um dos líderes mundiais de pesquisa no tema ${ }^{6}$. Entre os artigos mais baixados, temos também um escrito pelo psiquiatra Paulo Dalgalarrondo ${ }^{3}$, professor titular de psiquiatria da Universidade Estadual de Campinas (Unicamp), no qual demonstra que as pesquisas sobre as relações entre espiritualidade/religiosidade e transtornos mentais têm mobilizado psiquiatras brasileiros há mais de um século, concluindo haver "uma rica multiplicidade metodológica e de temas abordados nesses estudos sobre religiosidade e saúde mental", mas apontando que "a busca de teorias para nortear as pesquisas empíricas e uma maior articulação com as ciências sociais poderão contribuir para uma maior avanço nessa área"3.

Colaborando com essa longa história de pesquisas nessa temática no Brasil, a Revista de Psiquiatria Clínica vem publicando regularmente artigos no tema, tornando-se uma referência em Espiritualidade e Saúde, permitindo a divulgação de bons estudos na área, o que possibilita a educação continuada dos profissionais de saúde, bem como o intercâmbio entre pesquisadores. $\mathrm{O}$ fato de a Revista ser de livre acesso on line e estar indexada em importantes bases de dados internacionais, como a ISI, Scopus, PsycINFO, Embase e SciELO, permite ainda maior visibilidade da produção nela publicada.

Com o intuito de permitir um maior acesso dos clínicos e pesquisadores brasileiros ao que tem sido publicado na área da Espiritualidade e Saúde, foi criada a BVES - Biblioteca Virtual em Espiritualidade e Saúde (www.hoje.org.br/bves), em que são disponibilizados gratuitamente, em português e inglês, artigos e dissertações/ teses na área. Somente no ano de 2009, essas publicações científicas foram baixadas mais de 25 mil vezes na BVES.

$\mathrm{O}$ volume e a qualidade das evidências atualmente disponíveis têm levado a um crescente reconhecimento que espiritualidade se constitui em uma dimensão importante da vida das pessoas em todo o mundo, bem como a constatação de que as práticas e crenças religiosas dos pacientes influenciam o cuidado e a evolução dos problemas de saúde. Essa constatação tem gerado um esforço internacional de integrar a espiritualidade na prática médica. A maioria das faculdades de medicina dos Estados Unidos e algumas do Brasil já oferecem algum tipo de treinamento na área. Várias or- 
ganizações de saúde mundialmente relevantes, como a Organização Mundial de Saúde, o Joint Commission on Accreditation of Health Care Organizations e o American College of Physicians (EUA), têm enfatizado a importância de abordar questões de espiritualidade na prática clínica. Associações profissionais como o Royal College of Psychiatrists (do Reino Unido), a American Psychological Association e a World Psychiatric Association possuem departamentos ou grupos de interesse em Espiritualidade/Religiosidade.

O Brasil, pela sua dimensão, sua diversidade e tolerância religiosa, bem como sua crescente produção científica e relevância no cenário internacional, tem um grande potencial para ser um país líder no avanço do conhecimento e da integração da espiritualidade na saúde. É muito bom saber que a Revista de Psiquiatria Clínica tem assumido um papel de destaque nesse processo de ampliação das fronteiras do conhecimento humano, bem como de humanização dos cuidados em saúde.

\section{Referências}

1. Panzini RG, Rocha NS, Bandeira DR, Fleck MPA. Qualidade de vida e espiritualidade. Rev Psiq Clín. 2007;34(Supl.1):105-15.

2. Peres MFP, Arantes ACLQ, Lessa PS, Caous CA. A importância da integração da espiritualidade e da religiosidade no manejo da dor e dos cuidados paliativos. Rev Psiq Clín. 2007;34(Supl. 1):82-7.

3. Dalgalarrondo P. Estudos sobre religião e saúde mental realizados no Brasil: histórico e perspectivas atuais. Rev Psiq Clín. 2007;34(Supl. 1):25-33.

4. Elias ACA, Giglio JS, Pimenta CAM, El-Dash LG. Programa de treinamento sobre a intervenção terapêutica "relaxamento, imagens mentais e espiritualidade" (RIME) para re-significar a dor espiritual de pacientes terminais. Rev Psiq. Clín. 2007;34(Supl. 1):60-72.

5. Peres JFP, Simão MJP, Nasello AG. Espiritualidade, religiosidade e psicoterapia. Rev Psiq Clín. 2007;34(Supl. 1):136-45.

6. Greyson B. Experiências de quase-morte: implicações clínicas. Rev Psiq Clín. 2007;34(Supl. 1):116-25. 